\title{
INTRODUZINDO O CONCEITO DE AVALIAÇÃO POR RUBRICAS POR INTERMÉDIO DE OFICINAS: Análise de uma Experiência Piloto
}

\author{
Valesca Brasil Irala ${ }^{1}$ \\ Leandro Blass ${ }^{2}$ \\ Sonia Maria da Silva Junqueira ${ }^{3}$
}

\begin{abstract}
RESUMO
Este artigo busca descrever a experiência de uma oficina voltada à qualificação da avaliação de desempenho acadêmico via utilização de rubricas (BROOKHART, 2013; FRANCIS, 2018; HOWELL, 2014), realizada junto a estudantes da Licenciatura em Matemática de uma universidade pública no interior do Rio Grande do Sul. A pertinência da temática se dá pelo fato de que a formação inicial, de forma geral, dispensa poucas oportunidades aos licenciandos, ao longo dos seus cursos de Graduação, para refletirem e se apropriarem a respeito dos sentidos produzidos pela avaliação nos contextos de ensino. Dessa forma, a produção de espaços alternativos e complementares à sala de aula regular, como os promovidos por meio de oficinas, pode contribuir para ampliar as experiências dos graduandos a respeito da capacidade de se tornarem avaliadores mais qualificados no exercício dos seus papéis imediatos (como alunos, por meio da autoavaliação ou da coavaliação entre pares) ou futuros (como professores). Os resultados da experiência da oficina piloto apontam para a necessidade de ampliação das oportunidades coletivas para discussão sobre as práticas avaliativas, bem como instrumentalizar os licenciandos com ferramentas orientadas teoricamente com vistas a qualificar os procedimentos vinculados à avaliação, como pode ser o exemplo da avaliação via utilização de rubricas.
\end{abstract}

Palavras-chave: Avaliação. Desempenho. Rubricas. Formação inicial.

\section{INTRODUCING THE CONCEPT OF RUBRIC FOR ASSESSMENT THROUGH WORKSHOPS:} ANALYSIS OF A PILOT EXPERIENCE

\begin{abstract}
This article searches to describe the experience of a workshop aimed at qualifying the assessment of academic performance through the use of rubrics (BROOKHART, 2013; FRANCIS, 2018; HOWELL, 2014), held with students of the Undergraduate Degree in Mathematics of a public university in the interior of Rio Grande do Sul. The relevance of the theme is due to the fact that initial training, in general, dispenses with few opportunities for futures teachers, throughout their undergraduate courses, to reflect and appropriate themselves about the meanings produced by the assessment in the teaching contexts. Thus, the production of alternative and complementary spaces to the regular classroom, such as those promoted through workshops, can contribute to expand the experiences of undergraduates regarding the ability to become more qualified evaluators in the exercise of their immediate roles (as students, through self-assessment or peer co-evaluation) or future (as teachers). The results of the pilot workshop experience point to the need to expand collective opportunities for discussion about assessment practices, as well as to instrumentalize futures teachers with theoretically oriented tools, with a view to procedures linked to the assessment, such as the example of the assessment via the use of rubrics.
\end{abstract}

Keywords: Assessment. Performance. Rubrics. Initial training.

RECEBIDO EM: 13/1/2020

ACEITO EM: $11 / 6 / 2020$

\footnotetext{
1 Autora correspondente. Universidade Federal do Pampa (Unipampa) - Campus Bagé. Av. Maria Anunciação Gomes de Godoy, 1650 - Bairro Malafaia - CEP 96413-172. Bagé/RS, Brasil. http://lattes.cnpq.br/7316864301240506. https://orcid.org/0000-0001-6190-8440. valescairala@unipampa.edu.br.

2 Universidade Federal do Pampa (Unipampa) - Campus Bagé. http://lattes.cnpq.br/7385942137403019. https://orcid.org/0000-00032302-776X.

3 Universidade Federal do Pampa (Unipampa) - Campus Bagé. http://lattes.cnpq.br/4291668071705125. https://orcid.org/0000-00025616-5344.
} 
O formato de universidade, atualmente constituído pela tríade pesquisa-ensino-extensão, deve considerar que a produção de saber interconecta essas três instâncias em um movimento constante que se retroalimenta de "dimensões singulares (saber) e suas apresentações dessingularizadas (conhecimento)" (BEHARES, 2011, p. 82). Dito isso, dimensionamos que, quando pesquisadores se debruçam conceitualmente sobre um determinado campo epistemológico, é válido também o exercício de vinculá-lo a experiências singulares de compreensão e apropriação sobre ele, como forma de que, ao analisar tais experiências, seja possível também (re)configurar o olhar teórico sobre tal objeto, de modo a ponderá-lo a partir de outros pontos de vista, menos técnicos, mas igualmente válidos.

É nessa perspectiva que o projeto de pesquisa intitulado "Aprendizagens ativas e colaborativas: análise da percepção docente, do engajamento discente, da autorregulação e do processo avaliativo", vinculado ao Grupo de Pesquisa sobre Aprendizagens, Metodologias e Avaliação (Gama/cadastrado no Diretório de Grupos de Pesquisa do CNPq), aponta para a temática da avaliação não apenas pelo viés investigativo per se, mas também pelo desenvolvimento de um conjunto de palestras e oficinas voltado a diferentes públicos, bem como a instituição de novas incursões avaliativas por parte dos pesquisadores envolvidos no âmbito de suas experiências como docentes em componentes curriculares de Graduação e Pós-Graduação aos quais se vinculam, como forma de igualmente retroalimentar o campo teórico.

Neste trabalho, em especial, descreveremos a experiência de uma oficina piloto realizada no âmbito de uma Semana Acadêmica do Curso de Matemática-Licenciatura da Universidade Federal do Pampa (Unipampa), no Campus Bagé, ocorrida no primeiro semestre do ano de 2019. Atividades dessa natureza não são exclusivas para o público universitário e visam a integrar docentes da Educação Básica ao espaço acadêmico. Acabam participando, entretanto, como público majoritário, os estudantes de diferentes semestres, o que não deixa de ser uma experiência diferenciada da usual do cotidiano universitário, o qual, dada uma estrutura curricular ordenada prioritariamente de forma sequencial, obstaculiza que, na maior parte do tempo (especialmente em cursos noturnos, como é o caso da Matemática-Licenciatura da Unipampa), alunos de diferentes semestres possam compartilhar de forma mais sistemática vivências e saberes. São os espaços de Semanas Acadêmicas e outros similares a ele que propiciam, de maneira mais explícita, esse tipo de convivência, o que lhes converte em um rico cenário para apreensão de singularidades e agenciamento de novas reflexões teóricas por parte dos pesquisadores envolvidos.

Na seção seguinte faremos uma breve apresentação sobre a perspectiva por nós adotada no que diz respeito à avaliação no campo educacional, bem como apresentaremos uma síntese sobre nossa inserção no âmbito da avaliação via utilização de rubricas.

\section{NÓS, AFINAL, AVALIAMOS PERFORMANCE OU APRENDIZAGEM?}

$\mathrm{O}$ ato de avaliar pode ser considerado constitutivo do ser humano, uma vez que para qualquer tomada de decisão é preciso uma avaliação prévia de uma dada situação e dos agentes nela envolvidos, a fim de se obter um determinado resultado de forma mais qualificada e satisfatória. Quando voltamo-nos à avaliação direcionada aos contex- 
tos formais de ensino, devemos considerar que nem sempre ela ocupa o grau de centralidade que lhe é requerido (PERRENOUD, 1999), nem é tão comum o surgimento de abordagens que superem o excesso de "subjetividade arbitrária" ou bem o seu oposto, a "pseudo-objetividade matemática" (RAVELA; PICARONI; LOUREIRO, 2017, p. 233) no momento de avaliar os alunos, conforme apontam esses autores a partir de sua análise junto aos regulamentos sobre avaliação discente em diversos países da América Latina.

Os autores citados identificaram que em grande parte das instituições de ensino ocorre forte oscilação entre esses dois polos. A principal crítica apontada pelos autores, com a qual coincidimos, é a de que a subjetividade é inerente ao ato avaliativo e não se revela exatamente como um problema, mas sim acontece com o estabelecimento da arbitrariedade. A criação de rubricas é uma alternativa apontada por Ravela, Picaroni e Loureiro (2017, p. 240) para que se "explicite as intenções educativas, seus diferentes graus de cumprimento e o modo como o docente constrói sua valoração da performance do estudante", e acrescentamos, sobre quais pilares se constroem essas valorações.

É importante mencionar que, ainda que no contexto brasileiro se convencionou falar em avaliação da aprendizagem (LUCKESI, 2011), quando optamos por uma abordagem em termos de performance (ou por sua tradução mais usual em língua portuguesa, utilizando o conceito de "desempenho"), estamos assumindo o caráter realístico e situado que está implicado nesse constructo, em oposição ao conceito amplo e multidimensional da aprendizagem, em diálogo com o que apontam os pesquisadores norte-americanos Bjork e Bjork (2011) e Soderstrom e Bjork (2015), os quais têm se debruçado a investigar, pela abordagem da Psicologia, diversos processos vinculados a essa temática.

Já no campo educacional, ao contrário do que os autores revelam que ocorre na tradição das pesquisas em Psicologia, parece-nos problemático que, muitas vezes, ambos os constructos, aprendizagem e desempenho, venham sendo tratados como intercambiáveis, entendendo, grosso modo, que os tempos institucionais e a natureza das proposições didáticas seriam suficientes para dar conta de aprendizagens efetivas. É evidente que a instrução formal, viabilizada pelas instituições educativas, visa a facilitar a aprendizagem, que é associada a uma relativa estabilidade do conhecimento a longo prazo e a sua capacidade de retenção e transferência (BJORK; BJORK, 2011; SODERSTROM; BJORK, 2015) e é válido acrescentar, também, de sua transformação (SALVAT, 2008).

Em contrapartida, segundo os autores citados, o desempenho durante o processo de instrução formal pode ser, inclusive, um índice pouco confiável de que foi alcançada uma aprendizagem efetiva a longo prazo. Dito isso, é possível considerar como um pressuposto ilusório, instituído há bastante tempo no campo educacional, o fato de que, na condição de professores, possamos dispor de mecanismos suficientes para uma avaliação da aprendizagem. Nesses termos, consideramos que sim, dispomos de mecanismos para avaliarmos performances discentes a partir da seguinte definição: a performance "se refere às flutuações temporárias de comportamento ou conhecimento que pode ser observado e mensurado durante ou imediatamente após o processo de aquisição" (SODERSTROM; BJORK, 2015, p. 177). 
Os autores, em sua revisão da literatura da área, alertam que, apesar das evidências empíricas de que aprendizagem e desempenho não são interdependentes, identificam a resistência de professores e alunos em entenderem esses conceitos de forma distinta, fazendo com que, muitas vezes, adotem estratégias (de ensino, no caso dos primeiros ou de estudo, no caso dos segundos) menos eficientes em termos de levar a uma aprendizagem mais flexível e duradoura. Os erros e sua explicitação, um trabaIho consistente em cima do que revelam, a refacção de tarefas, entre outros exemplos, durante o processo de instrução formal ou durante a prática, podem ser evidências consideradas desfavoráveis para o desempenho (em que há tradicionalmente valoração positiva do acerto imediato), mas podem trazer ganhos substantivos em termos de aprendizagens duradouras.

Compreendendo então que os tempos e condições didáticas das instituições educativas só permitem uma avaliação da performance e não das aprendizagens solidificadas a longo prazo, entendemos, assim como diversos autores apontam na literatura, que devemos insistir em uma avaliação para a aprendizagem (MORENO OLIVOS, 2016; SCHLATTER; GARCEZ, 2012), pois acreditamos, coincidindo com Brown (2005, p. 81), que "a avaliação é, provavelmente, a coisa mais importante que podemos fazer para ajudar que nossos alunos aprendam". Ou seja, entendemos que uma avaliação que privilegie modelos mecanizados, copistas, desconexos dos demais conhecimentos não tem condições de contribuir, pelo desempenho que é exigido ante a esse tipo de proposta, para atingir níveis mais significativos de compreensão e transformação de qualquer área do saber, o que é especialmente esperado, por exemplo, na formação de estudantes do Ensino Superior, visando a suas atuações profissionais futuras cada vez com demandas mais complexas.

Muitas queixas corriqueiras dos docentes em relação a possíveis "más escolhas" dos alunos e estratégias adotadas por eles sobre seus objetos disciplinares estão diretamente relacionadas à maneira como é desenhada a avaliação e como ela se "acomoda" no jogo didático que é levado a cabo em um dado espaço institucional. Na próxima seção, discorreremos brevemente sobre o conceito de rubricas e argumentaremos o porquê ele tem se tornado um potencializador de uma avaliação para $a$ aprendizagem.

\section{A OPÇÃO PELAS RUBRICAS}

À medida que vivemos já há algumas décadas e, de forma mais acentuada, nos últimos anos, a Era dos rankings entre instituições pertencentes à unidade federativa e também do país em relação a outras nações no que se refere ao conceito de qualidade (MARCOVITCH, 2018; MOROSINI et al., 2016) em termos educacionais, tanto no Ensino Superior quanto na Educação Básica (BARREYRO, 2008; SCHNEIDER; NARDI, 2014), a construção de mecanismos que não apenas revelem maior transparência ao processo avaliativo, mas que possam contribuir para, de fato, fazer avançar o percurso formativo dos estudantes em prol de aprendizagens mais complexas e dinâmicas, torna-se um imperativo que transcende a prática docente diária e seus limites institucionais, como outrora costumava-se fazer. 
Concluímos que, no contexto institucional no qual a oficina foi desenvolvida, a utilização de rubricas pode ser entendida como um dispositivo alternativo de inovação na avaliação (NORAINI et al., 2015; FLUCK; HILLIER, 2016; LOCK et al., 2018; VON DAVIER, ZHU; KYLLONEN, 2017), compreendida aqui como uma forma de inovação situada perante as estratégias avaliativas dominantes na instituição de ensino em questão (não exclusivas a ela), em que a atribuição (por parte do professor) ou recebimento (por parte do aluno) de uma "nota" se sobrepõe a aspectos formativos mais amplos. Ao adquirir esse caráter inovador, a disseminação dos preceitos subjacentes, bem como a elaboração de estratégias para recepção e disseminação da abordagem avaliativa por nós defendida, são cruciais para que mais docentes (tanto os acadêmicos de Licenciaturas em formação inicial, público principal da oficina, em suas práticas futuras, quanto os pares dos ministrantes envolvidos, ou seja, outros docentes universitários) se encorajem a debruçarem-se sobre a prática avaliativa a fim de transformá-la como "parte do esforço para que haja um avanço do conhecimento" (SALVAT, 2008, p. 84).

Espera-se, nessa perspectiva, que esses professores (e/ou futuros professores) atuem como protagonistas e compositores (SPIEGEL, 1999), ancorados no vasto campo teórico da avaliação e, mais especificamente, voltando-se à criação e à utilização de rubricas na avaliação do desempenho estudantil, entendidas por nós como tarefas docentes altamente criativas e, portanto, de natureza fundamentalmente autoral (ainda que seja possível que um professor apenas utilize/adapte uma rubrica já criada por outros docentes de sua própria instituição ou disponíveis em sites especializados no assunto existentes na Internet, mesmo que, até o momento, tais sites sejam produzidos majoritariamente em língua inglesa, pois a utilização de rubricas em vários países anglo-saxões é usual há bastante tempo).

A rubrica pode ser definida, de forma genérica, como um dispositivo/artefato que busca uma descrição detalhada das expectativas do professor em relação ao desempenho do aluno de forma ampla ou em tarefas específicas, apresentando um caráter tanto descritivo quanto preditivo para a produção desse desempenho. Uma variação do modelo prevê a construção de tais expectativas em conjunto com os discentes, tornando-os mais participativos no processo de avaliação (LUDKE, 2003; PRAT BRAU; RAMAJO; RODRÍGUEZ, 2014; PUTRI, 2016; URIOS et al., 2015; SIMPSON; MCKAY, 2013; ATKINSON; LIM, 2013).

Frisamos que a rubrica não é um instrumento e sim um dispositivo/artefato de meta-avaliação (ELLIOT, 2011), porque ela pode ser útil a diversos instrumentos avaliativos e a muitos aspectos formativos não captados normalmente pelos instrumentos tradicionais (exemplo, a participação em aula, a integração entre os membros de um grupo ao longo da execução de um trabalho em equipe, etc.); inclusive, pode ser desenhada para utilização em provas escritas que são instrumentos considerados, tanto pela tradição da área de avaliação no Brasil (LUCKESI, 2011; HOFFMANN, 2012) quanto por muitos educadores e estudantes, como as grandes vilãs do cenário avaliativo. Ao mesmo tempo, de forma controversa, são, até hoje, tratadas ainda como o instrumento mais legitimado (SANTO; LUZ, 2012; SANTOS; IRALA, 2018). 
A rubrica, que pode ser construída a partir de diferentes formatos (KING et al., 2013), é elaborada com base em critérios ou, como preferimos chamar, em dimensões da performance discente definidas para o cumprimento eficaz de uma tarefa ou de um conjunto de tarefas estipuladas. A quantidade de dimensões é variável de acordo com a complexidade da tarefa ou ao quanto de detalhamento o professor (ou este em conjunto com os alunos) queira propor para fracionar a qualidade de sua execução. Além das dimensões (ou critérios), também é necessário definir quantos níveis de adequação a esses critérios são suficientes para dar conta de explicitar os diferentes graus de qualidade da performance, que podem surgir em relação a um determinado critério.

Em geral, ao propor desenhos avaliativos por meio de rubricas, temos optado preferencialmente por operar com: a) seis níveis, tais como "excelente", "muito bom", "bom", "aceitável", "inadequado" e "evidência insuficiente"; b) com quatro níveis, com nomenclaturas variáveis, como "excelente", "adequado", "necessita melhoras" e "não atende"; ou c) com três níveis, por exemplo, "estratégico", "resolutivo" e "insuficiente" (esse último, de três níveis, foi o utilizado na oficina piloto). Há implicações conceituais, semânticas e práticas nas escolhas efetuadas (nomenclatura e número de níveis e critérios); portanto as decisões tomadas merecem ser constantemente ajustadas a cada nova experiência de desenvolvimento e estabelecimento de uma rubrica, o que justifica a importância do caráter eminentemente autoral que está implicado no momento de adotá-la no processo avaliativo.

Após a definição da quantidade e nomenclatura utilizada em um dos níveis, é realizada a descrição detalhada do conteúdo de cada nível em relação ao seu respectivo critério. O grau de completude da descrição e a capacidade de diferenciação entre os níveis são determinantes para uma compreensão adequada das expectativas pontuadas por parte do estudante, bem como por parte do professor, e facilitará o seu trabalho no momento de efetivamente utilizá-la para fornecer feedback aos alunos, de forma que essas devolutivas sejam suficientemente produtivas para qualificar suas performances futuras.

Na próxima seção traremos uma descrição do desenvolvimento da oficina bem como uma análise não exaustiva de seus procedimentos, a fim de compreender a validade da proposta para buscar qualificá-la na oferta de oficinas futuras que tenham o objetivo de disseminar a utilização de rubricas na avaliação.

\section{DESCRIÇÃO E ANÁLISE DA OFICINA PILOTO}

Introduzimos a seção apresentando o que entendemos por oficina, objeto de nossa análise neste artigo. Para defini-la, inspiramo-nos em Russo (2005), que discorreu sobre o gênero conferência acadêmica. A partir dela, compreendemos que uma oficina é um gênero presente nas esferas escolares, acadêmicas ou corporativas (também sendo recorrente no contexto brasileiro o uso do termo em inglês workshop), que se define por uma situação grupal na qual, perante um auditório em princípio iniciante no tópico abordado, um ou mais instrutores/ministrantes, em um tempo relativamente curto, proporcionam momentos práticos (e teóricos, em segundo plano) de introdução e/ou atualização de um assunto específico e atual. Como finalidades retóricas que esse gêne- 
ro deve buscar para "alcançar o objetivo final de persuadir ou convencer", para captar a atenção da audiência de forma satisfatória, deverá "ensinar, deleitar e comover" (RUSSO, 2005, p. 189).

Tendo em conta essas finalidades retóricas, desenhamos a oficina piloto intitulada "Como utilizar rubricas: um recurso para potencializar a avaliação". Ela foi aplicada junto ao grupo que, ao todo, atingiu 28 participantes, dos quais 26 eram alunos de Matemática-Licenciatura de diferentes semestres, 1 era professora da Educação Básica e 1 era professora universitária. A duração total da oficina foi de 1 hora e 30 minutos.

A preparação do ambiente da sala de aula em que a atividade se desenvolveu não foi menos relevante para o planejamento, uma vez que projetamos as atividades para que sejam realizadas com as classes dispostas em formato de $U$, "apresentando uma proposta de distribuição do mobiliário que permite aproximar-se de todos os alunos com relativa facilidade" (SANTOS, 2007, p. 72). Essa opção, de fato, tem impacto no desenvolvimento das atividades, à medida que foram recorrentes as interações individualizadas dos três ministrantes (autores deste artigo) com os participantes ao longo das diferentes tarefas propostas.

Os participantes preencheram o Termo de Consentimento Livre e Esclarecido para uso de voz e imagem para fins de pesquisa acadêmica, uma vez que, com vistas à geração de dados, a oficina foi gravada em áudio e vídeo, bem como foram realizados inúmeros registros fotográficos de seus diferentes momentos. Além disso, a oficina contou com a presença de duas observadoras externas (observação não participante): uma bolsista de Iniciação Científica e uma discente de Mestrado, que tem como foco de sua pesquisa a utilização de rubricas no Ensino Superior. A primeira produziu um registro narrativo (YUNI; URBANO, 2005) por meio de notas de campo (BOGDAN; BIKLEN, 1994) em tempo real, com o intuito de gerar informações "de primeira mão" das situações vivenciadas na oficina, as quais pudessem ser válidas para uma análise a posteriori dos pesquisadores envolvidos, bem como contrastá-las com a percepção dos próprios ministrantes e com os demais registros efetuados, entre eles os fotográficos, também realizados por ela. A segunda manipulou os equipamentos de áudio e vídeo utilizados para gerar os dados audiovisuais produzidos também para análise a posteriori.

Iniciada a oficina de fato, os participantes foram solicitados a responder a seguinte questão: "O que vem em sua mente quando pensa em avaliação da aprendizagem?" Para registrar as respostas recorremos ao uso dos smartphones, ou seja, os participantes, por meio de uma ferramenta gratuita de Sistema de Resposta da Audiência ou Web-based audience response system (ARS), como amplamente se conhece na literatura internacional (na oficina utilizamos um desses sistemas disponíveis na Internet, o Mentimeter $^{4}$ ), foram orientados a acessar o endereço eletrônico indicado e a responder à questão aberta mencionada, mas limitados ao uso de, no máximo, por submissão, três palavras-chave ou expressões do que, para eles, significasse a resposta.

O endereço eletrônico do Mentimeter é https://www.mentimeter.com/ e está disponível em língua inglesa. 
Little (2016), ao apresentar características encontradas no Mentimeter, identifica os benefícios de seu uso para atividades de sala de aula, as quais são igualmente válidas para uma oficina dessa natureza, principalmente dado o curto período de tempo previsto para a sua execução. Alguns dos benefícios apontados pela autora são os seguintes: a) fornecimento de feedback imediato das respostas produzidas; b) melhoria do engajamento da audiência (o que tem sido comprovado em várias pesquisas com a utilização desse tipo de sistema, tais como nas de Habel e Stubbs (2014) e Funnell (2017) entre outros); c) oferta de anonimato das respostas, buscando facilitar discussões posteriores (não gerando medo entre os participantes em fornecer respostas possivelmente equivocadas ou não esperadas pelos pares ou pelos docentes); e d) facilidade e agilidade do uso (desde que haja acesso à Internet e os participantes disponham de um smartphone), pois basta acessar o endereço eletrônico indicado e fornecer o código gerado pela questão fornecido pelos docentes ministrantes da atividade.

O próprio sistema gera, à medida que os participantes vão respondendo à questão, uma nuvem de palavras, em tempo real, com o conjunto de resultados da audiência. Por meio de uma projeção, os participantes podem acompanhar a modificação das respostas conforme o aumento de inserções e, além disso, o sistema permite que seja habilitado que um mesmo participante envie mais de uma submissão (o que lhes foi orientado a fazer na oficina, caso achassem necessário). O resultado da nuvem de palavras gerada na oficina piloto pode ser visualizado pela Figura 1.

Figura 1 - Nuvem de palavras - Questão inicial

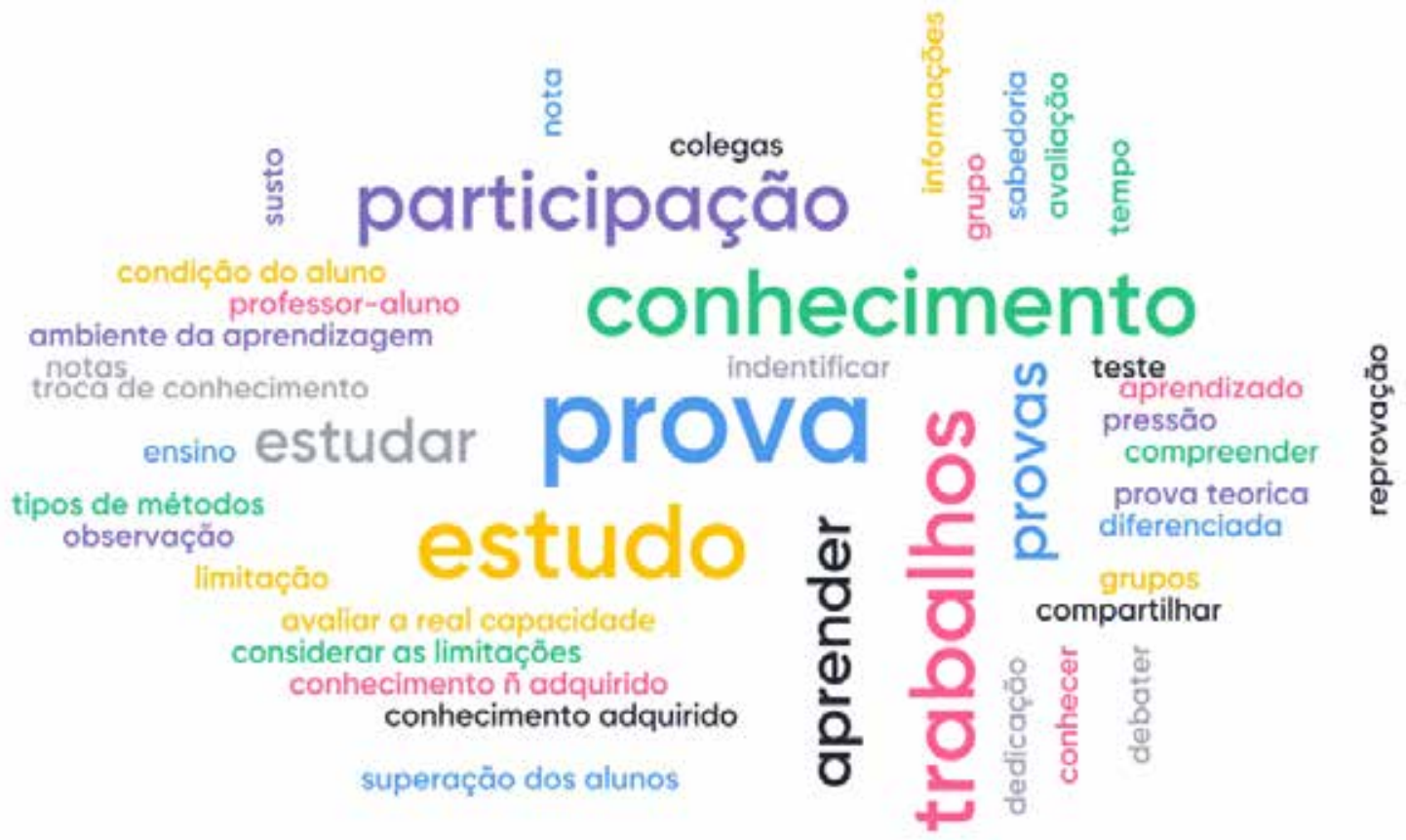

Fonte: Elaborada pelos autores (dados da pesquisa). 
A Figura $1^{5}$ mostra-nos o panorama dos sentidos produzidos sobre avaliação pelo conjunto dos participantes, em que destacamos, pelo tamanho da fonte, que o maior número de respostas foi associado ao vocábulo "prova" (ou similares, tais como "provas", "prova teórica" e "teste"). Esse resultado vai ao encontro do que identificaram Santos e Irala (2018) em sua pesquisa realizada no mesmo contexto institucional em que a oficina foi aplicada, porém junto a professores e não a estudantes, como é, neste caso, a grande maioria dos participantes. Nos achados por elas encontrados, mesmo entre os professores que mais diversificam seus instrumentos de avaliação, há hierarquização da prova sobre os demais instrumentos utilizados, além da presença da forte crença de que essa é a melhor opção a ser tomada pelos docentes perante as turmas mais numerosas. Isso corrobora que a cultura avaliativa em que estão imersos esses participantes (alunos de Graduação) estabelece grande associação entre avaliação e seus instrumentos mais comumente conhecidos: primeiramente a "prova" e, em segundo lugar, a utilização genérica do vocábulo "trabalhos". Observa-se, nos dados gerados, a fraca associação da avaliação aos seus possíveis objetivos, dada a escassez de verbos utilizados nos dados, dos quais destacamos os seguintes: "conhecer", "compreender" e "compartilhar" (embora usados, cada um, possivelmente por apenas um participante). Chama a atenção também a presença de vocábulos de conotação negativa, tais como "susto", "pressão" e "limitação", além da utilização do vocábulo "reprovação", indicando associação entre avaliação e um consequente e já previsível e possível insucesso.

Depois de realizada essa pesquisa inicial, com a nuvem de palavras projetada a todos os participantes, os ministrantes estimularam o debate a respeito dos resultados. Diante do silêncio inicial dos estudantes de Graduação, a única docente universitária como participante da oficina fez suas considerações. Ainda com os participantes pouco confortáveis para expor verbalmente suas opiniões, os ministrantes adotaram o procedimento estratégico da formulação de perguntas (RUSSO, 2005, p. 196), que, segundo a autora, tem "poder didático", "agilizam o desenvolvimento temático" e "permitem captar a atenção do auditório". A seguir, a reprodução de algumas perguntas espontâneas formuladas no momento da discussão, as quais chamam atenção:

Figura 2 - Dados extraídos da gravação em vídeo do primeiro momento

Sonia: Quando vocês pensam a avaliação de uma prova que vocês tenham participado, que o professor corrigiu e avaliou, quando termina e você olha a sua nota, você tem bem claro o processo, você está de acordo com aquela nota?

A maioria balança a cabeça sinalizando que "não" e uma participante verbaliza "nem sempre".

Valesca: (...) Vocês acham que a avaliação tem um fim no resultado de reprovar ou aprovar?

Silêncio e expressões de seriedade do público ante a pergunta.

Sonia: Se eu tirar zero eu escondo ou rasgo? Não é assim? Risos coletivos e resposta em coro "é". Se eu tirar uma nota alta eu tiro foto e boto lá no Face (referindo-se à rede social Facebook)? Vários risos e balanço de cabeças concordando, além de inúmeras conversas paralelas mobilizadas pela pergunta.

Fonte: Elaborada pelos autores.

Mantivemos a nuvem tal como foi gerada pelo sistema, sem modificações nas inadequações de ordem linguística. 
As perguntas utilizadas nesse momento como estratégias argumentativas para mobilizar o auditório cumpriram o seu propósito. O silêncio inicial foi quebrado a partir daí e, mesmo evitando, em geral, verbalizarem suas opiniões no coletivo (o fizeram prioritariamente para os pares que estavam ao lado ou de forma privada a algum dos três ministrantes que circularam todo o tempo da oficina entre os participantes), com a natureza dos questionamentos efetuados (contendo exemplificações muito próximas de suas realidades) e com o procedimento tático do humor (RUSSO, 2005, p. 205), foi se viabilizando rapidamente a adesão do auditório para compreender a natureza dos argumentos que viriam nos momentos subsequentes e, inclusive, para ponderarem suas observações.

A partir desse momento, duas participantes, licenciandas de final de curso, expuseram suas opiniões. Uma delas, inclusive, contou explicitamente que sua colocação tinha um duplo lugar discursivo (GRIGOLETTO, 2008), tanto como aluna quanto como professora, pois já havia passado por todos os estágios supervisionados obrigatórios do curso e experimentado a vivência de exercer o papel de avaliadora nessas ocasiões. Nas palavras dela, "zero não significa que aquele aluno não adquiriu nada" e, no processo avaliativo, é preciso dar oportunidade para o aluno demonstrar um novo desempenho. A segunda, ainda trazendo um exemplo de sua posição de aluna, aponta a situação de um diálogo comum entre alunos e professores: "Ah, professor, mas eu estudei"; e o professor contesta: "mas não foi suficiente" (expressando ar de lamento diante dessa "hipotética" situação).

Partindo desse gancho, uma das ministrantes (Sonia), já conduzindo para o próximo momento da oficina, questiona: "E vocês sabem por que não foi suficiente?" Essa pergunta buscava associar a ideia de que a correção deve ser efetuada com base em critérios (ou, como já apontamos no referencial teórico, o termo preferencialmente utilizado por nós, dimensões da performance discente) e que tais critérios precisam ser bem-definidos de antemão por quem corrige e bem-compreendidos por quem recebe a correção, a fim de que a avaliação, de fato, contribua para um avanço do estudante naquele aspecto avaliado. Assim, foi proposto que, em duplas, os participantes se colocassem no papel de avaliadores e atribuíssem notas para três resoluções diferentes de uma questão referente ao conteúdo de Matemática de Funções Quadráticas (a questão é a que segue na Figura 3).

\section{Figura 3 - Questão proposta}

(FAAP - SP) Uma indústria produz, por dia, $x$ unidades de determinado produto, e pode vender tudo o que produzir a um preço de $\mathrm{R} \$ 100,00$ a unidade. Se $\mathrm{x}$ unidades são produzidas a cada dia, o custo total, em reais, da produção diária é igual a $x^{2}+20 x+700$. Para, portanto, que a indústria tenha lucro diário de $\mathrm{R} \$ 900,00$, qual deve ser o número de unidades produzidas e vendidas por dia?

Fonte: SILVA (2020).

A estratégia adotada é conhecida como roleplaying (jogo de papéis), a qual "prevê que uma situação específica (real ou hipotética) seja apresentada a estudantes ou profissionais" (FILATRO; CAVALCANTI, 2018, p. 176), levando-os a vivenciar uma experiência na "perspectiva de outras pessoas". No caso do público em questão, sendo a 
maioria alunos de Licenciatura, o movimento de se colocarem no lugar de avaliadores é uma experiência ou ainda não conhecida ou muito pouco conhecida (como era o caso das estudantes que já haviam passado pelo estágio supervisionado, mas, mesmo nesses casos, é perceptível que o deslocamento do lugar discursivo de aluno para o de professor e, mais ainda para o de avaliador, não é uma tarefa simples). Dito isso, percebeu-se que, mesmo após terem recebido o material, pareciam pouco seguros ou confortáveis do que deveriam fazer. Foi então que uma das ministrantes detalhou a tarefa esperada nesses termos:

Figura 4 - Dados extraídos da gravação em vídeo (designação da tarefa)

Valesca: (...) Vamos supor três provas diferentes, de três alunos diferentes. No caso, a prova 2 é a minha, a prova 1 é a da professora Sonia e a prova 3 foi a do profe Leandro. Então, nós vamos brincar que nós somos os alunos de vocês respondendo essa questão. Então, de zero a cem, vocês têm que dar uma nota (...)

Fonte: Elaborada pelos autores.

A partir desse momento, o que se identificou é que os participantes se sentiram mais mobilizados para realizar a atividade, em especial por se tornarem, momentaneamente, os "professores dos professores ministrantes", ainda que fosse uma brincadeira. Não sugerimos nenhum critério de avaliação, e, nessa etapa da oficina, cada participante pôde avaliar livremente as resoluções. Conforme mostra a Figura 5, a resolução 1 tinha a resposta organizada "passo a passo", apresentando etapas completas da sistematização para chegar ao resultado do problema, além de mostrar a solução de forma algébrica e gráfica. A resposta à questão está explícita no final da resolução.

Figura 5 - Resolução 1

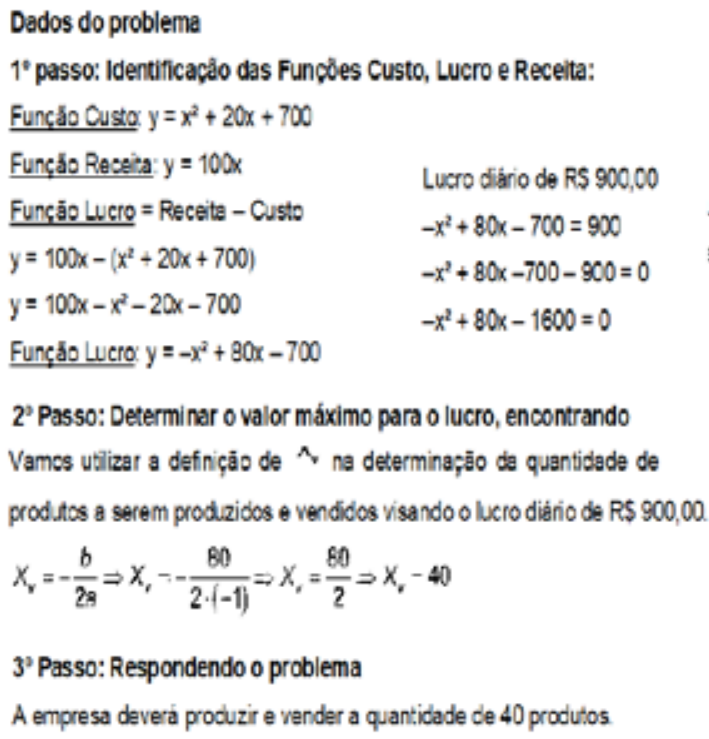
Lucro diário de RS 900,00 $-x^{2}+80 x-700=900$ $-x^{2}+80 x-700-900=0$ $-x^{2}+80 x-1600=0$

$4^{\circ}$ Passo: Apresentando a interpretaçāo da solução gráfica
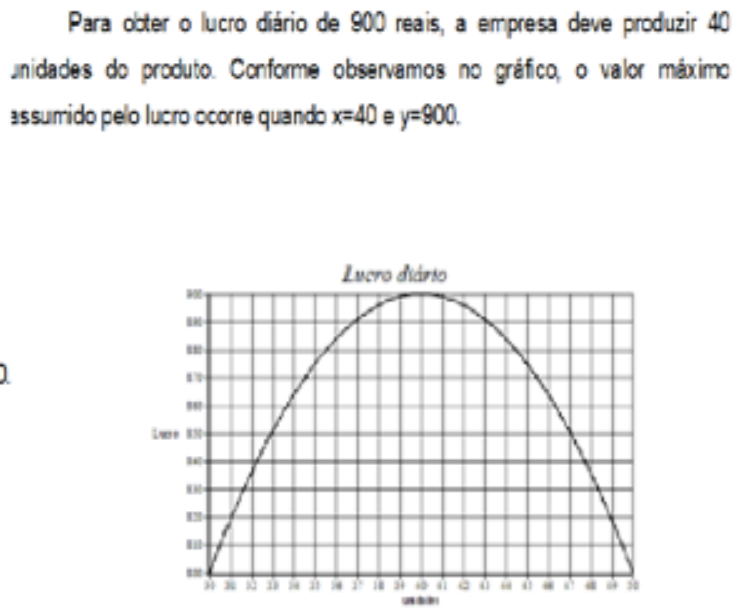
A resolução 2, embora apresente um passo inicial de forma apropriada, com o estabelecimento correto da relação entre lucro e receita, mostra erro de sinal quando é realizada algebricamente a eliminação dos parênteses, o que gerou erro no resultado final. A resolução apresenta apenas a solução algébrica da questão, e a resposta foi indicada no final da resolução, conforme observa-se na Figura 6.

Figura 6 - Resolução 2

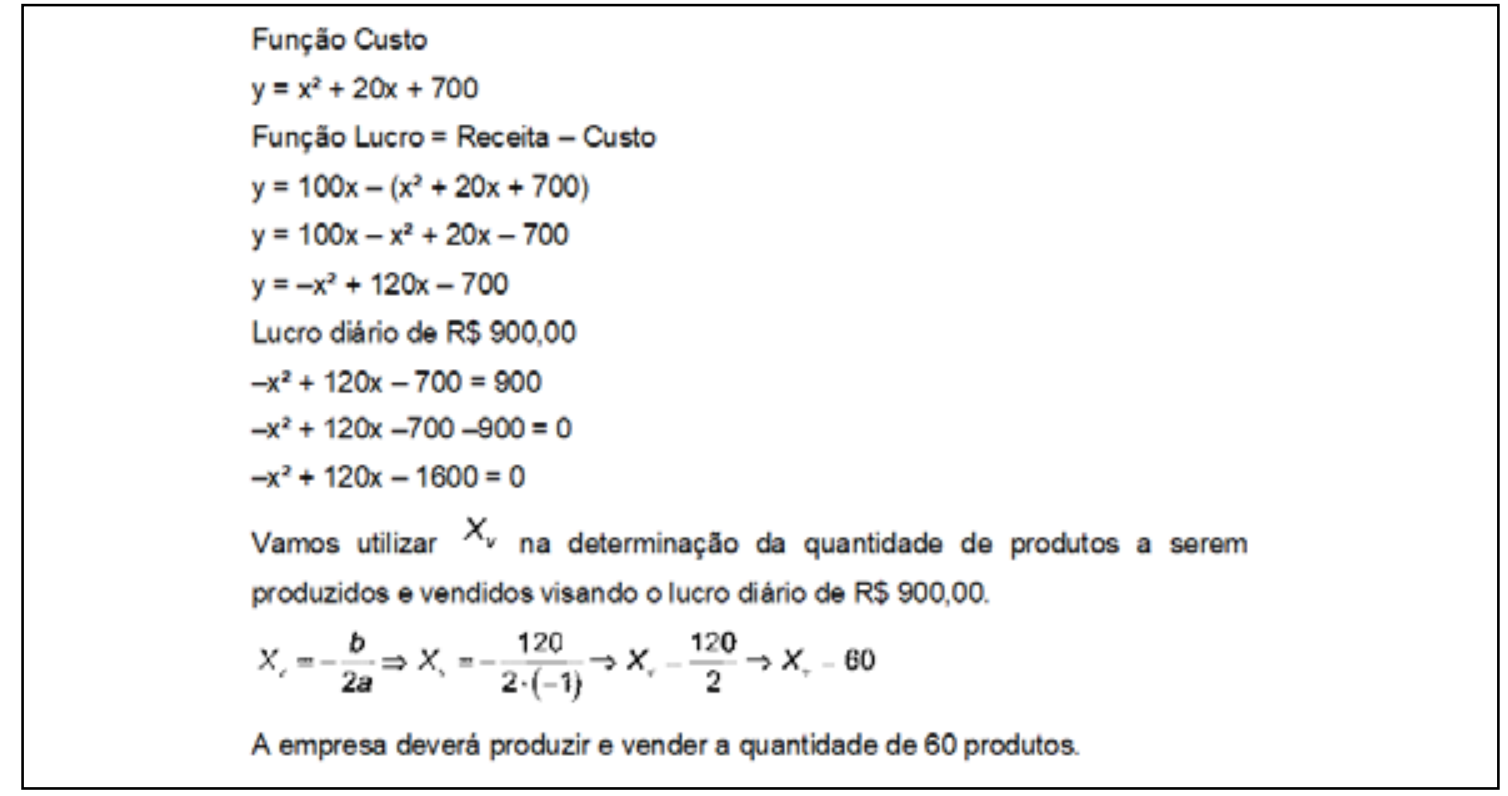

Fonte: Elaborada pelos autores.

A resolução 3 está resolvida de maneira totalmente incorreta, não havendo coerência nos cálculos apresentados. A questão foi respondida de forma implícita, não sendo explicitada qual seria a resposta ao problema proposto. A resolução 3 também apresenta somente a solução algébrica.

Figura 7 - Resolução 3

\begin{tabular}{|l}
$y=x^{2}+20 x+700$ \\
$R S 100,00$ \\
RS 900,00 \\
\\
$x^{2}+20 x+700-100=900$ \\
$x^{2}+20 x+600-900=0$ \\
$x^{2}+20 x+300=0$ \\
$x=-20202+4.1 .3002 .1=x=-20402=x^{\prime}=10 \quad \ldots . \quad x^{\prime \prime}=-30$ (não serve) \\
$x=10$
\end{tabular}

Fonte: Elaborada pelos autores.

Neste ponto da oficina ainda não haviam sido apresentadas as rubricas aos participantes. Nessa etapa, os resultados foram variados e as notas atribuídas atingiram alto grau de amplitude entre elas, pois cada dupla de avaliador baseou-se em suas próprias 
métricas. No final dessa rodada pedimos que mostrassem as notas atribuídas. Identificamos que, nessa situação, a menor amplitude foi para a resolução 1 , que variou entre 90 e 100 pontos entre as diferentes duplas de avaliadores. Já a resolução 2 apresentou uma variação que foi entre 37,5 e cem pontos. Por último, a resolução 3 mostrou uma variação que oscilou de zero e 50. Pedimos que justificassem os critérios adotados para atribuir essas notas, porém, as poucas duplas que se manifestaram verbalmente mencionaram primeiramente os erros de sinais e depois a "lógica" que o aluno utilizou para montar a equação, independentemente de ter chegado ao resultado correto ou não. De forma geral, nesta etapa percebe-se a dificuldade na explicitação de critérios menos vagos ou mesmo justificar com clareza o porquê de a pontuação "descontada" ser essa e não outra.

Em seguida, entregamos aos participantes as rubricas de avaliação desenvolvidas para o fim específico de avaliar as respostas à questão da Figura 3. Solicitamos novamente que as duplas avaliassem as três resoluções; no entanto, a partir de agora, deveriam usar a rubrica exposta na Tabela 1 . Na rubrica proposta operamos com três dimensões da performance discente e atribuímos uma pontuação máxima variável entre cada dimensão, o que vem a estabelecer um grau de hierarquia entre elas, na qual a resolução do problema em si apresenta leve sobreposição às demais. Nessa rubrica em específico, também operamos com três níveis, no qual o "estratégico" é assim denominado para se referir ao nível mais exitoso possível de ser atingido em cada dimensão, e o nível "insuficiente" o menos exitoso.

Como já abordamos anteriormente, nossas experiências como docentes que utilizam rubricas têm nos mostrado que um número maior de níveis é mais produtivo para gerar um retrato mais detalhado das dimensões em suas diferentes possibilidades, dada a variabilidade normalmente encontrada no interior das turmas. Quando o número de níveis é menor, o mapeamento das diferenças dentro do próprio nível é dificultado. No caso do que propusemos na oficina, a diferença entre as três resoluções era bem marcada para fins didáticos (e também para agilizar a tarefa, dado o pouco tempo da oficina), o que não ocorre em uma situação real de sala de aula, em que a gradação das dificuldades possíveis de serem identificadas é muito mais complexa.

Tabela 1 - Rubrica para avaliar as questões matemáticas

\begin{tabular}{|c|c|c|c|}
\hline \multicolumn{4}{|c|}{ Produto: Resolução de questão } \\
\hline Dimensões & Estratégico & Resolutivo & Insuficiente \\
\hline $\begin{array}{l}\text { Compreendeu } \\
\text { o problema } \\
\text { e aplicou a } \\
\text { informação } \\
\text { (30 pontos) }\end{array}$ & $\begin{array}{l}\text { (...) Identificou fatores } \\
\text { essenciais para a } \\
\text { resolução do problema. } \\
\text { Explicou o passo a passo } \\
\text { dos procedimentos } \\
\text { adotados. } \\
\text { (30 pontos) }\end{array}$ & $\begin{array}{l}\text { (...) Compreendeu o } \\
\text { suficiente para resolver } \\
\text { o problema. Explicou } \\
\text { parte do passo a passo } \\
\text { dos procedimentos. } \\
\text { (20 pontos) }\end{array}$ & \begin{tabular}{l} 
(...) Não compreendeu \\
o suficiente para \\
resolver o problema. \\
Não apresentou \\
organização e \\
sistematização dos \\
procedimentos. \\
\multicolumn{1}{c}{ (5 pontos) }
\end{tabular} \\
\hline
\end{tabular}




\begin{tabular}{|c|l|l|l|}
\hline $\begin{array}{c}\text { Usou } \\
\text { representações } \\
\text { matemáticas } \\
\text { (30 pontos) }\end{array}$ & $\begin{array}{l}\text { (...) Usou } \\
\text { desenvolvimento } \\
\text { matemático algébrico e } \\
\text { gráfico que claramente } \\
\text { retrata o caminho para } \\
\text { a solução do problema. } \\
\text { (30 pontos) }\end{array}$ & $\begin{array}{l}\text { (..) Usou } \\
\text { desenvolvimento } \\
\text { matemático que } \\
\text { retrata, em parte, como } \\
\text { solucionar o problema. }\end{array}$ & $\begin{array}{l}\text { (..) Usou } \\
\text { representação com } \\
\text { erros que fornece } \\
\text { pouca ou nenhuma } \\
\text { informação para } \\
\text { a resolução do } \\
\text { problema. } \\
\text { (5 pontos) }\end{array}$ \\
\hline $\begin{array}{c}\text { Respondeu o } \\
\text { problema } \\
\text { (40 pontos) }\end{array}$ & $\begin{array}{l}\text { (...) Solucionou } \\
\text { corretamente o } \\
\text { problema seguindo } \\
\text { todos os passos para } \\
\text { chegar à solução } \\
\text { adequada. Interpretou o o } \\
\text { resultado do problema. }\end{array}$ & $\begin{array}{l}\text { (...) Solucionou } \\
\text { parcialmente o } \\
\text { problema. Cometeu } \\
\text { erros matemáticos em } \\
\text { alguns passos. Resposta } \\
\text { errada baseada em } \\
\text { um desenvolvimento } \\
\text { inapropriado. } \\
\text { (25 pontos) }\end{array}$ & $\begin{array}{l}\text { (...) Não apresentou } \\
\text { solução do problema. }\end{array}$ \\
\hline (40 pontos)
\end{tabular}

Fonte: Elaborada pelos autores.

Depois de realizada a nova avaliação das resoluções, agora orientada pela rubrica, solicitamos que respondessem oralmente à questão: "Mudou a sua avaliação?" Nesse momento, os participantes sinalizavam gestualmente ou balançando a cabeça que sim, que havia ocorrido mudanças (apenas uma dupla sinalizou que não ocorreu mudança em relação à primeira avaliação, quando não haviam utilizado a rubrica). Analisando as pontuações atribuídas, identificamos, após a utilização da rubrica, uma menor discrepância entre as notas de cada dupla, especialmente no que se refere à resolução 2 e à resolução 3, as quais demandavam dos "avaliadores iniciantes", participantes da oficina, maior compreensão da própria questão para identificar em quais dimensões houve "falha" e em que momento do desenvolvimento algébrico ela havia ocorrido.

Finalizado a etapa da avaliação das resoluções matemáticas, recorremos a um momento de natureza lúdica, mas igualmente importante para a compreensão da proposta, a fim de demonstrar que as rubricas, de fato, são dispositivos pertinentes para potencializar qualquer processo de avaliação. Conduzimos, então, nesse momento quase final, a avaliação de três diferentes tipos de biscoitos, em alusão às três resoluções matemáticas (e igualmente "brincamos" que os biscoitos haviam sido feitos, respectivamente, pelos ministrantes). Nessa etapa apresentamos aos participantes os três diferentes tipos de biscoitos e a rubrica por meio da qual realizariam a avaliação (Tabela 2). 
Tabela 2 - Rubrica para avaliar os biscoitos

\begin{tabular}{|l|l|l|l|}
\hline $\begin{array}{l}\text { Dimensões } \\
\text { avaliativas }\end{array}$ & $\begin{array}{l}\text { Uma maravilha! (3 } \\
\text { pontos) }\end{array}$ & Comestível (1 ponto) & $\begin{array}{l}\text { Não, obrigado (Zero } \\
\text { ponto). }\end{array}$ \\
\hline Aparência & $\begin{array}{l}\text { Olhar para o biscoito me } \\
\text { deixa com água na boca. } \\
\text { O biscoito parece caseiro. }\end{array}$ & $\begin{array}{l}\text { Pode haver partes } \\
\text { exageradas ou } \\
\text { irregulares, mas quero } \\
\text { comê-lo. }\end{array}$ & $\begin{array}{l}\text { Isso é um biscoito? } \\
\text { Objeto apresenta formas } \\
\text { irregulares ou está } \\
\text { queimado. }\end{array}$ \\
\hline Gosto & $\begin{array}{l}\text { Delicioso! Só quero } \\
\text { comer mais e mais! } \\
\text { É possível identificar } \\
\text { sabores marcantes dos } \\
\text { ingredientes. }\end{array}$ & $\begin{array}{l}\text { Já provei biscoitos } \\
\text { melhores, mas mesmo } \\
\text { assim o comeria } \\
\text { novamente. }\end{array}$ & $\begin{array}{l}\text { Isso tem um sabor } \\
\text { estranho. Uma mordida } \\
\text { já foi o suficiente para } \\
\text { não seguir comendo-o. }\end{array}$ \\
\hline Textura & $\begin{array}{l}\text { O biscoito é macio e não é é } \\
\text { quebradiço. }\end{array}$ & $\begin{array}{l}\text { O biscoito é crocante, } \\
\text { mas é quebradiço. }\end{array}$ & $\begin{array}{l}\text { O biscoito quebra os } \\
\text { meus dentes. }\end{array}$ \\
\hline
\end{tabular}

Fonte: Rubrica adaptada e traduzida pelos autores de Quick Rubric (2020).

Na proposta, já de posse dos biscoitos e da rubrica, os participantes foram orientados a avaliar individualmente a primeira dimensão (aparência) sem experimentar os biscoitos. Assim, foram avaliados os três tipos de biscoitos na dimensão aparência. Em seguida, após a degustação dos biscoitos, foram orientados a avaliar as demais dimensões (gosto e textura), considerando, também, os critérios apresentados na rubrica.

Concluída a avaliação por todos os participantes, inclusive com a atribuição de uma nota dada conforme a pontuação expressa na rubrica, pedimos que contrastassem como foi avaliar utilizando a rubrica desde o início do processo. Em resposta a essa questão, os participantes relataram ter encontrado maior facilidade para concluir a tarefa, quando comparada ao primeiro momento da avaliação das questões matemáticas sem a rubrica, pois os critérios estavam postos desde o início, inclusive vinculados a uma pontuação distinta para cada nível alcançado, o que, segundo os participantes, facilitou e agilizou o processo de avaliação e de atribuição de notas. A mesma aluna de fim de curso que antes havia se manifestado no início da oficina em relação ao sentido da nota "zero", nesse momento ponderou que, mesmo o biscoito mal avaliado (que recebeu "zero" porque estava queimado e excessivamente apimentado), deveria ter a possibilidade de receber uma pontuação maior pela "tentativa" de ter sido elaborado. Compreendemos que a crença da "tentativa" (muito presente nos dias atuais como possível justificativa para "alcançar" uma aprovação) pode ser prejudicial para promover uma concepção que visa a incidir na avaliação para $a$ aprendizagem e não que conduza para a mera promoção.

Na sequência, explicamos que, em nosso entendimento, a rubrica não pode ser vista como um instrumento de avaliação, mas, sim, como um dispositivo de meta-avaliação (como já apontamos anteriormente no referencial teórico deste artigo), a qual pode ser aplicada para todos os tipos de performance, potencializando qualquer processo de avaliação, o que ficou demonstrado aos participantes pelo exemplo da avaliação da qualidade dos biscoitos. A seguir, evidenciamos algumas observações pontuadas pelos formadores a fim de dar um fechamento argumentativo que validasse a lógica construída até aquele momento (efeito do uso da rubrica perante os alunos e como é feita a sua socialização, facilidade na correção, empoderamento e autoria do professor, etc.), de forma a incidir sobre a decisão dos participantes de, em suas experiências imediatas ou futuras, também adotarem a rubrica em suas práticas avaliativas: 
Figura 8 - Dados extraídos da gravação em vídeo (fechamento) ${ }^{6}$

Sonia: O que a gente tem notado na nossa prática? Que às vezes a gente perde um tempinho. Vamos colocar esse perde entre aspas, para fazer [[a rubrica]]. Só que depois que a gente faz, você potencializa a correção. Facilita corrigir. A gente ganha muito depois na correção. Eu costumo falar para os meus alunos que aqueles niveis é como se fosse um degrau. Se ele tá perdendo, ele desce um degrau (...).

Leandro: (...) Eu disponibilizo lá no MOODLE [[a rubrica]] e eles já sabem no que vão ser avaliados (...). Eu percebi que fica muito mais claro para o aluno e a gente ganha muito, porque o resultado final melhora. Eu percebi que a qualidade dos trabalhos melhora. Tira um monte de dúvidas. Aproxima o aluno do professor. Ele passa a enxergar o professor como facilitador. Eles estão sempre me procurando: "Ah, professor, eu li lá na rubrica que tem tal coisa. Como eu faço isso?" Eu não tenho dúvida que potencializa muito o ensino e aí justifica a ideia da oficina (...).

Valesca: (...) Vocês têm todo um caminho na vida de professores pela frente, em que vocês vão avaliar sempre os alunos, porque essa demanda sempre vai existir. E vocês qualificarem e refletirem sobre avaliação não é algo simples de se fazer e nem algo estático, que vocês fizeram uma vez e tem uma receita pronta para fazer sempre. Tanto não tem receita que as nossas rubricas estão sempre mudando. Tanto que a gente aplica uma rubrica e tenta melhorar, tenta aperfeiçoar. Tenta fazer que ela fique mais transparente (...).

Fonte: Elaborada pelos autores.

Como última atividade propusemos aos participantes que, novamente utilizando o Mentimeter, apresentassem a impressão que tiveram da oficina, respondendo, por meio de três palavras-chave, à pergunta: O que vem em sua mente ao avaliar essa oficina? Os vocábulos escolhidos para se referir ao uso de rubricas corroboram a ideia de que a proposta apresenta caráter inovador para o público participante neste contexto institucional dado. A Figura 9 representa a nuvem de palavras gerada automaticamente a partir das respostas dos participantes.

Figura 9-O que vem em sua mente ao avaliar a oficina

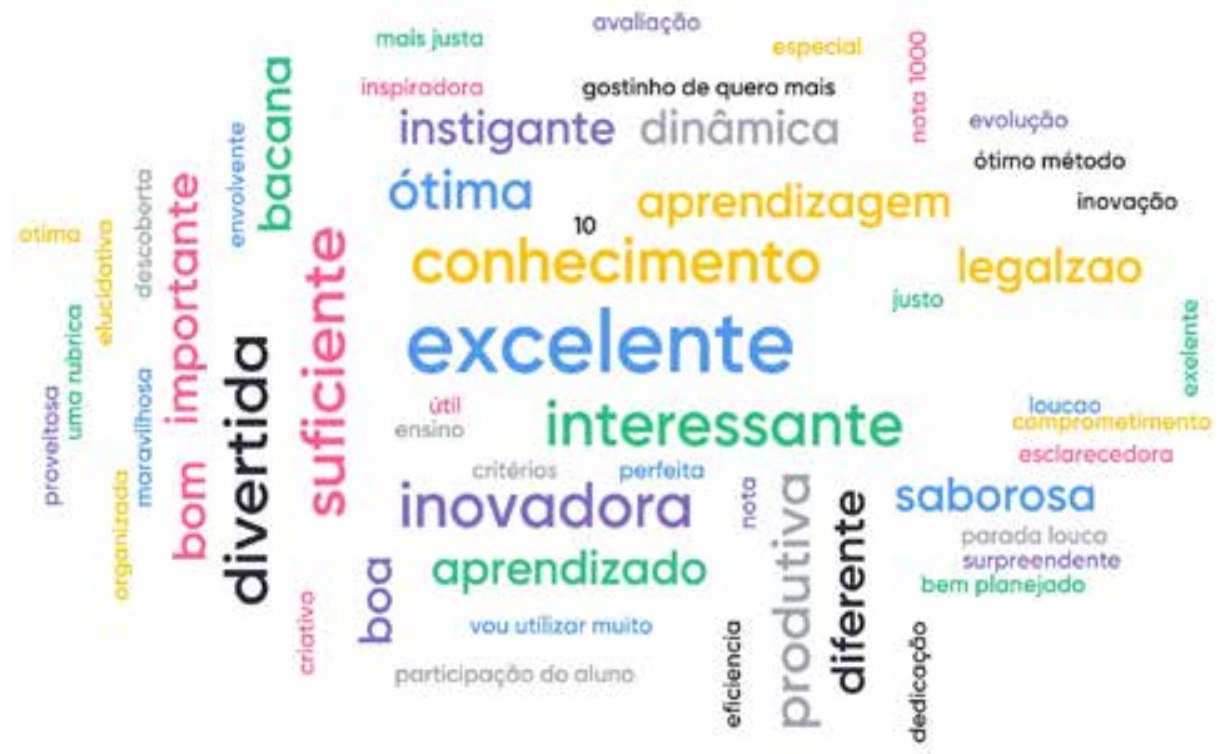

Fonte: Elaborada pelos autores (dados da pesquisa).

\footnotetext{
Os vocábulos dispostos entre dois colchetes são comentários do transcritor a partir do vídeo gravado, a fim de recuperar os referentes que são omitidos no fluxo da fala, dada a contextualização da interação; porém, ao realizar a transcrição, é preciso retomá-los para facilitar a leitura.
} 
Conforme pode ser verificado por meio da nuvem ${ }^{7}$ de palavras (Figura 9), entendemos que a oficina alcançou um resultado positivo, o que nos leva a inferir o alcance da mensagem objetivada por intermédio da prática conduzida de mostrar aos participantes o potencial das rubricas de avaliação, destacando-se como um dispositivo de meta-avaliação aplicável a uma infinidade de tarefas e com caráter de potencializar processos de avaliação em ambientes formais de ensino.

\section{CONSIDERAÇÕES FINAIS}

Propusemos, neste trabalho, descrever o desenho de uma oficina voltada à disseminação da utilização de rubricas em contextos formais de ensino, visando a potencializar a prática avaliativa. Experiências dessa natureza, para atingirem o objetivo proposto, precisam adotar procedimentos estratégicos e táticos pertinentes à situação comunicativa em questão, levando em conta o tempo predeterminado para a atividade e as características gerais do público-alvo, por mais diverso que ele possa ser (no caso da oficina piloto ministrada desde alunos ingressantes no curso de Matemática - a grande maioria, alunos de fim de curso -, uma docente da Educação Básica e uma docente universitária).

Considerando que o tópico "avaliação", do lugar discursivo que queríamos mobilizar, o de "professor avaliador", não era um lugar comumente ocupado pela maioria dos participantes em suas práticas diárias, a estratégia de solicitar que eles se vissem como "professores" dos próprios ministrantes da oficina operou como um efeito positivo para mobilizá-los para a temática de uma outra forma, imputando um outro grau de responsabilidade e perspectiva, sem, entretanto, causar desconforto, mas, pelo contrário, as atividades ocorreram em tom de brincadeira e descontração, em uma atmosfera de interação plenamente agradável, como ficou evidenciado pela nuvem de palavras gerada ao término da oficina, pelas notas de campo da observadora externa e pelo visionamento da gravação em vídeo. Os resultados obtidos na oficina piloto descrita, por outro lado, foram produtivos também para nossas próprias reflexões como docentes e pesquisadores que buscam amparo teórico no campo da avaliação, mas que, ao mesmo tempo, retroalimentam as próprias teorias a partir dos encontros e vivências ímpares vividos nas salas de aula.

Sabemos que reconfigurar os procedimentos avaliativos demanda um movimento que envolve muitos fatores, dada uma tradição muito forte que ainda não atribui à avaliação a atenção e o cuidado necessários para, de fato, qualificar o ensino, visando à obtenção de desempenhos mais satisfatórios a curto prazo e a aprendizagens mais sólidas a longo prazo. Avaliar e ser avaliado para "reprovar" ou para "aprovar" tem um peso ainda muito relevante na crença de muitos atores desse processo.

O trabalho de desconstrução dessas crenças não se dá em um momento pontual de uma oficina, mas, sim, com a circulação contínua de ideias, de trocas de experiências, de fazeres e da presença de novas crenças nos contextos institucionais em que circulamos. Seguir planejando, atuando e refletindo sobre todos esses momentos é o que nos

Mantivemos a nuvem tal como foi gerada pelo sistema. 
cabe nesse cenário. Por último, vale dizer que quanto mais transformarmos a atividade avaliativa em uma tarefa menos individual e mais coletiva, mais benefícios atingiremos, como temos diagnosticado a partir de nossas experiências ao planejar e utilizar rubricas no contexto universitário em que atuamos.

\section{AGRADECIMENTOS}

À bolsista de Iniciação científica do CNPq (2018-2019), Eduarda Loraine Estevez, pelas notas de campo produzidas. À mestranda Liziane Padilha Mena, pela gravação em vídeo efetuada na oficina piloto. Aos participantes da oficina, sem os quais os dados não seriam gerados.

\section{REFERÊNCIAS}

ATKINSON, D.; LIM, S. L. Improving assessment processes in Higher Education: Student and teacher perceptions of the effectiveness of a rubric embedded in a LMS. Australasian Journal of Educational Technology, v. 29, n. 5, p. 651-666, 2013.

BARREYRO, G. B. De exames, rankigns e mídia. Avaliação: Revista da Avaliação da Educação Superior, v. 13, n. 3, p. 863-868, 2008.

BEHARES, L. E. Enseñanza y producción de conocimiento. Montevidéu: Departamento de Publicaciones de la Universidad de la República, 2011.

BOGDAN, R.; BIKLEN, S. Investigação qualitativa em educação: uma introdução à teoria e aos métodos. Porto: Porto Editora, 1994.

BJORK, E. L.; BJORK, R. A. Making things hard on yourself, but in a good way: Creating desirable difficulties to enhance learning. In: GERNSBACHER, M. A. et al. (org.). Psychology and the real world: essays illustrating fundamental contributions to society. New York, NY: Worth Publishers, 2011. p. 56-64.

BROOKHART, S. How to create and use rubrics for formative assessment and grading. Alexandria, Virginia, USA: ASCD, 2013.

BROWN, S. Assessment for Learning. Learning and Teaching in Higher Education, v. 1, 2005, p. 81-89. Disponível em: http://eprints.glos.ac.uk/id/eprint/3607. Acesso em: 2 jan. 2020.

ELLIOT, L. Meta-avaliação: das abordagens às possibilidades de aplicação. Ensaio: aval. Pol. Públ. Educ., Rio de Janeiro, v. 19, n. 73, p. 941-964, out./dez. 2011.

FRANCIS, J. E. D. Linking Rubrics and Academic Performance: an Engagement Theory Perspective. Journal of University Teaching \& Learning Practice, v. 15, n. 1, 2018. Disponível em: http://ro.uow.edu.au/jutlp/ vl15/iss1/3. Acesso em: 15 jan. 2019.

FILATRO, A.; CAVALCANTI, C. Metodologias Inov-ativas na educação presencial, a distância e corporativa. São Paulo: Saraiva, 2018.

FLUCK, A.; HILLIER, M. Innovative assessment with eExams. Proceedings of Australian Council for Computers in Education Conference. Brisbaine, Queensland, Australia, sept./oct. 2016.

FUNNELL, P. Using audience response systems to enhance student engagement and learning in information literacy teaching. Journal of Information Literacy, v. 11, n. 2, p. 28-50, 2017.

GRIGOLETTO, E. Do lugar discursivo à posição-sujeito: os movimentos do sujeito-jornalista no discurso de divulgação científica. In: MITTMANN, S.; GRIGOLETTO, E.; CAZARIN, E. (org.). Práticas discursivas e identitárias: sujeito e língua. Porto Alegre: Nova Prova, 2008. p. 47-65.

HABEL, C.; STUBBS, M. Mobile phone voting for participation and engagement in a large compulsory law course. Research in Learning Technology, v. 22, 2014. Disponível em: https://doi.org/10.3402/rlt. v22.19537. Acesso em: 6 jan. 2020.

HOFFMANN, J. Avaliação mediadora: uma prática em construção da pré-escola à universidade. Porto Alegre: Mediação, 2012. 176 p.

HOWELL, R. Grading rubrics: hoopla or help? Innovations in Education and Teaching International, v. 51, n. 5, p. 400-410, 2014. 
KING, J. et al. Evaluative Rubrics: a Method for Surfacing Values and Improving the Credibility of Evaluation. Journal of Multidisciplinary Evaluation, v. 9, n. 21, p. 11-20, 2013.

LITTLE, C. Technological Review: Mentimeter Smartphone Student Response System. Compass: Journal of Learning and Teaching, v. 9, n. 3, 2016.

LOCK, J. et al. Navigating the Tensions of Innovative Assessment and Pedagogy in Higher Education. The Canadian Journal for the Scholarship of Teaching and Learning, v. 9, n. 1. 2018. Disponível em: https:// ir.lib.uwo.ca/cjsotl_rcacea/vol9/iss1/8. Acesso em: 15 jan. 2019.

LUDKE, M. O trabalho com projetos e a avaliação na educação básica. In: ESTEBAN, M. T.; HOFFMAN, J.; SILVA, J. F. (org.). Práticas avaliativas e aprendizagens significativas. Porto Alegre: Mediação, 2003.

LUCKESI, C.C. Avaliação da aprendizagem escolar: estudos e proposições. São Paulo: Cortez, 2011. 272 p. MARCOVITCH, J. Monitoramento das métricas de desempenho acadêmico. In: MARCOVITCH, J. (org.). Repensar a universidade: desempenho acadêmico e comparações internacionais. São Paulo: Com-Arte; Fapesp, 2018. p. 95-110.

MORENO OLIVOS, T. Evaluación del aprendizaje y para el aprendizaje: reinventar la evaluación en el aula. México: UAM; Unidad Cuajimalpa, 2016.

MOROSINI, M. C. et al. A qualidade da educação superior e o complexo exercício de propor indicadores. Revista Brasileira de Educação, v. 21, n. 64, p. 13-37, 2016.

NORAINI, Idris et al. Innovating Higher Education: redesigning assessment. International Journal of Management and Applied Science, v. 1, n. 8, p. 96-98, 2015.

PERRENOUD, P. Avaliação: da excelência à regulação das aprendizagens - entre duas lógicas. Porto Alegre: Artmed, 1999. 183 p.

PRAT BAU, M. N.; RAMAJO, B. P.; RODRÍGUEZ, A. L. La capacidad de análisis en la formación de trabajadores sociales: diseño de una rúbrica de evaluación de la competencia. Cuadernos de Trabajo Social, v. 27, n. 2, p. 365-374, 2014.

PUTRI, A. EFL teachers' understanding in developing lesson plan. Indonesian EFL Journal, v. 2, n. 1, p. 1-11, 2016.

QUICK RUBRIC. What is a rubric. 2020. Disponível em: https//quickrubric.com/about/what-is-a-rubric. Acesso em: 13 jan. 2020.

RAVELA, P.; PICARONI, B.; LOUREIRO, G. ¿Cómo mejorar la evaluación en el aula? Montevidéu: Magro, 2017. 277 p.

RUSSO, G. La conferencia académica. In: SEVERINO, L. (org.). Los textos de la ciencia: principales clases del discurso académico-científico. Córdoba: Comunic-arte, 2005. p. 189-220.

SALVAT, B. Aprendizajes, conexiones y artefactos: la producción colaborativa del conocimiento. Barcelona: Gedisa, 2008.

SANTO, E. E.; LUZ, L.C. Avaliação das aprendizagens no nível superior: avaliar para quê? Dialogia, São Paulo, n. 16, p. 141-154, 2012.

SANTOS, M. A. Gestão de sala de aula e crenças em professores do 1o Ciclo do Ensino Básico. 2007. Tese (Doutorado) - Universidade do Minho, Instituto de Educação e Psicologia, 2007.

SANTOS, N. C. C.; IRALA, V. Avaliação da aprendizagem no contexto universitário: um estudo preliminar no campus Bagé da Unipampa. In: SALÃO INTERNACIONAL DE ENSINO, PESQUISA E EXTENSÃO, 2018, Santana do Livramento. Anais [...]. Bagé: Unipampa, 2018. V. 10. Disponível em: http://seer.unipampa.edu. br/index.php/siepe/article/view/34202/19636. Acesso em: 15 jan. 2019.

SCHLATTER, M.; GARCEZ, P. Línguas adicionais na escola: aprendizagens colaborativas em inglês. Erechim: Edelbra, 2012.

SCHNEIDER, M.; NARDI, E. O Ideb e a construção de um modelo de accountability na educação básica brasileira. Revista Portuguesa de Educação, v. 27, n. 1, p. 7-28, 2014.

SILVA, M. N. P. Problemas envolvendo funções do 2o Grau. Brasil Escola. Disponível em: https://brasilescola.uol.com.br/matematica/problemas-envolvendo-funcoes-2-grau.htm. Acesso em: 12 jan. 2020.

SODERSTROM, N. C.; BJORK, R. A. Learning Versus Performance: an Integrative Review. Perspectives on Psychological Science, v. 10, n. 2, p. 176-199, 2015.

SPIEGEL, A. Docente protagonista: docente compositor. Buenos Aires: Novedades Educativas, 1999. $223 \mathrm{p}$. 
SIMPSON, Z.; MCKAY, T. M. Assessment Rubrics: artefacts that speak in tongues? Per Linguam, v. 29, n. 1, p. 15-32, 2013.

VON DAVIER, A. A.; ZHU, M.; KYLLONEN, P. C. (org.). Innovative assessment of collaboration. Cham, Switzerland: Springer, 2017. 330 p.

URIOS, M. I. et al. Generic Skill Development and Learning/Assessment Process: use of rubrics and student validation. Journal of Technology and Science Education, v. 5, n. 2, p. 107, 2015.

YUNI, J.; URBANO, C. Mapas y herramientas para conocer la escuela: investigación etnográfica e investigación-acción. 3. ed. Córdoba: Brujas, 2005. 